\title{
AND THERAPEUTIC SCIENCE
}

\section{DIFFERENCES IN DYNAMIC AND POSTURAL STABILITY BASED ON DEGREE OF DISABILITY IN PATIENTS WITH NONSPECIFIC CHRONIC LOWER BACK PAIN: AN OBSERVATIONAL STUDY}

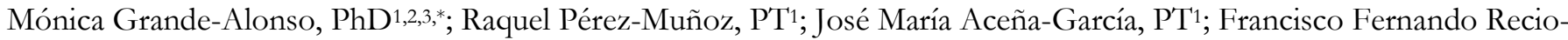 \\ Mateo, $\mathrm{PT}^{1}$; Diego Pro-Marín, PT ${ }^{1,3}$; Roy La Touche, $\mathrm{PhD}^{1,2}$ \\ 1. Departamento de Fisioterapia, Facultad de Ciencias de la Salud. Centro Superior de Estudios Universitarios La Salle. Universidad Autónoma de Madrid. 28023 \\ Madrid (España) \\ 2. Motion in Brains Research Group, Institute of Neuroscience and Sciences of the Movement (INCIMOV). Centro Superior de Estudios Universitarios La Salle. \\ Universidad Autónoma de Madrid. 28023 Madrid (España) \\ 3. Instituto de Rehabilitación Funcional La Salle, Aravaca, Madrid, España
}

Correspondence:

Mónica Grande-Alonso, PT, PhD Facultad de Ciencias de la Salud, Centro Superior de Estudios Universitarios La Salle. Calle La Salle 10, 28023 Madrid, España Telephone: 917401980 E-mail: monica.grande@irflasalle.es.

\section{Conflict of Interest:}

The authors declare that they have no conflict of interest. This project has not been presented at any scientific event.

Funding:

The authors declare that they have not received funding/compensation for the development of this research.

Ethics Committee:

CSEULS-PI-126/2016

DOI:

htpps://doi.org/10.37382/jomts.v3i1.471

\section{Manuscript Receipt:}

21-July-2021

Manuscript Acceptance:

28-July-2021

Licensed under: CC BY-NC-SA 4.0

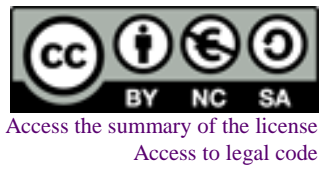

\begin{abstract}
Objetive: The main objective of this study was to analyze whether there were differences in dynamic balance and postural stability in relation to the level of disability in patients with chronic low back pain.

Methodss: This is an observational study in which 60 patients with nonspecific chronic low back pain were included. All patients received a sociodemographic questionnaire, the visual analogue scale (VAS) and a series of self-reported psychological scales. To complete the evaluation, physical tests were performed in which dynamic balance and postural stability were measured.
\end{abstract}

Results: Student's t-test revealed that there were significant differences between the groups in dynamic balance with the right leg and the left leg. In contrast, there were no significant differences between the groups for the reach functional test in forward direction, left direction and right direction.

Conclusion: In conclusion, our study demonstrates that patients with chronic low back pain with high levels of disability present significantly poorer dynamic balance compared with those with low levels of disability. In contrast, no significant differences were found between the groups in terms of static stability.

Keywords: Nonspecific chronic low back pain, Disability, Dynamic balance, Postural stability, Self-efficacy, Kinesiophobia, Catastrophism. 


\section{INTRODUCTION}

Lower back pain (LBP) is defined as pain located between the lower rib cage and upper limits of the gluteal muscles (Wadell, 2004). LBP is a complex multidimensional condition that is expected to affect a large percentage of the population at some point in their lives (Hoy et al., 2010; Starkweather et al., 2016; Sadler et al., 2017).

Studies have reported that LBP is the most prevalent musculoskeletal disorder, a condition that presents a high risk of chronification (Murray and Lopez, 2013; Starkweather et al., 2016; La Touche et al., 2019). Chronic LBP (CLBP) is defined as pain lasting longer than 3 months, with approximately $90 \%$ of cases of a nonspecific nature (Woolf and Pfleger, 2003; Hoy et al., 2010; Herndon et al., 2015). The prevalence of CLBP in the general population is approximately $38 \%$, with a higher incidence among middle-aged women. CLBP is one of the most common causes of work absenteeism and disability, interfering significantly with daily life activities. CLBP can therefore be considered a primary health problem in Western society, one that is associated with high socioeconomic costs (Krismer et al., 2007; Rossignol et al., 2009; Hoy et al., 2012; Wajswelner et al., 2012).

The chronification process can lead to maladaptive neuroplastic changes at the cortical and medullary level as a result of central sensitization processes (Hashmi et al., 2013), changes that can be aggravated by psychosocial factors (Zusman, 2002; Wideman and Sullivan, 2011; Hashmi et al., 2013). Factors such as low self-efficacy, catastrophism and kinesiophobia have been associated with an increased risk of developing disability in individuals with CLBP (Hartvigsen et al., 2018).

Disability is one of the most common psychosocial variables in LBP (Anema et al., 2009; Incidence and Collaborators, 2017). A significant percentage of patients with LBP have biopsychosocial factors, as well as comorbidities and pain management mechanisms, which influence their experience of pain and their perception of their disability (Hartvigsen et al., 2018). A number of authors have also observed that greater physical disability and greater pain intensity in the lumbar region are correlated with poorer functional status (Brech et al., 2012). Among the physical and functional variables affected in this population are dynamic balance and postural stability (Tsigkanos et al., 2016). Specifically, balance is a complex process that involves the interaction of sensory organs that identify movements and the central nervous system, which communicates with the musculoskeletal system to execute the movements (Lee and Ahn, 2018). Balance is an indispensable element in all activities of daily life and is a high-level integration process that includes adaptive and predictive mechanisms, musculoskeletal elements, proprioceptive senses, and the vestibular and visual organs (Yavuzer et al., 2006; Lee and Ahn, 2018).

When discussing balance, we also need to consider dynamic balance and static balance. Static balance (or postural stability) has been studied in situations where the vision is blocked and in demanding static body positions. In these situations, patients with CLBP present greater body oscillations and more impaired static balance than individuals without CLBP (Tsigkanos et al., 2016; Berenshteyn et al., 2019). Good dynamic balance is critical to the functional capacity in activities of daily living, and dynamic balance is typically reduced in patients with CLBP (Hooper et al., 2016). The maintenance of postural balance in static and dynamic conditions is essential for any functional activity (Brech et al., 2012). In individuals with CLBP, the degree of control varies, such that daily tasks are compromised and pain recurs (della Volpe et al., 2006; Brumagne et al., 2008).

The main objective of this study was to analyze whether there were differences in dynamic balance and postural stability in relation to the level of disability in patients with CLBP. The secondary objective was to determine whether there were differences in psychosocial variables according to the degree of disability in patients with CLBP. 


\section{METHODS}

\section{Study design}

A cross-sectional study with a nonprobabilistic sample was conducted to assess static stability and dynamic equilibrium according to the degree of lumbopelvic disability among patients with nonspecific CLBP (NSCLBP). The study was conducted in accordance with the Strengthening the Reporting of Observational Studies in Epidemiology (STROBE) statement (von Elm et al., 2008). The study also followed the principles of the Declaration of Helsinki and was approved by the La Salle University Ethics Committee (CSEULS-PI126/2016). Written informed consent was obtained from all participants.

\section{Patients}

The consecutive nonprobabilistic convenience sample consisted of 60 patients with NSCLBP. Patients were classified as having "high" or "low" lumbopelvic disability based on a median score split on the Roland Morris Questionnaire. Group 1 consisted of 30 patients who registered a low level of lumbopelvic disability, and group 2 was composed of 30 patients who registered a high level of lumbopelvic disability. The sample was recruited from the La Salle Functional Rehabilitation Institute, the local community through flyers, posters, and social media and from outpatients of a primary health care center in Alcobendas, Madrid, Spain.

\section{- Inclusion criteria}

Patients were selected if they met all of the following inclusion criteria: a) low back pain for at least 6 months; b) low back pain of a nonspecific nature; c) not having undergone back surgery; d) no specific spinal disease (e.g., malignancy, inflammatory joint and bone diseases); and e) 18 to 65 years of age. The participants were also asked not to take any medication $24-48 \mathrm{~h}$ before the evaluation.

\section{- Exclusion criteria}

Patients were excluded if they met any of the following exclusion criteria: a) presence of neurological signs (e.g., perceived weakness in the lower limbs); b) a diagnosed psychiatric disorder or severe cognitive impairment; c) illiteracy; d) difficulties understanding or communicating; and e) insufficient Spanish language comprehension to follow the measurement instructions.

\section{Procedures}

After providing written informed consent, all participants underwent an initial assessment by completing a sociodemographic questionnaire that collected data on sex, date of birth, marital status, educational level, medication intake, and professional activity. The participants were also asked a series of questions regarding pain: pain intensity on a visual analog scale (VAS) and the duration and frequency of pain in the last 30 days. The participants then completed a series of self-administered questionnaires on fear of movement, pain catastrophizing, chronic pain self-efficacy, and patient-perceived disability. This phase lasted approximately $30 \mathrm{~min}$.

Before starting the functional tests, the length of each leg was measured from the anterior superior iliac spine to the internal malleolus with the patient in the supine position. Once a patient was included in the study, the first measurement was performed, which consisted of performing the dynamic balance test (Y-Balance Test) in 3 directions: anterior, posteromedial, and posterolateral. Three measurements were made with each leg and for each direction, obtaining the mean values for the statistical analysis. The test was performed to an accuracy of $0.5 \mathrm{~cm}$. To express the reach distance as a percentage of limb length, the normalized value was calculated as the sum of the 3 directions of reach divided by 3 times the limb length, then multiplied by 100 (Plisky et al., 2009).

Lastly, the postural stability test was performed using the Functional Reach Test, in which postural stability was evaluated in 3 directions: anterior, lateral-right, and lateral-left. Three measurements were taken in each direction to obtain the arithmetic mean for each patient.

For both tests, the physiotherapist performed a demonstration for the participant. During the performance of the tests, a physiotherapist assisted 
and supervised the correct performance of the tests, while another recorded the measurements.

\section{Variables}

\section{- Main variables}

Lumbar disability. Physical disability due to LBP was assessed using the Spanish version of the Roland Morris Disability Questionnaire, which has been shown to have acceptable psychometric properties (Cronbach 0.9140) (Kovacs et al., 2002). This selfadministered questionnaire consists of 24 items with a total score ranging from 0 to 24 , with higher scores indicating higher levels of disability (Kovacs et al., 2002). The participant responds by considering their current situation (over the past $24 \mathrm{~h}$ ).

Postural stability. Postural stability was assessed using the Multidirectional Functional Reach test, which has demonstrated good intrarater, inter-rater and test-retest reliability (Newton, 2001). Static stability was measured in 3 directions (forward, right lateral and left lateral) through movements performed by the participant (in $\mathrm{cm}$ ) by shifting the center of gravity to the limits of the base of support, while the feet remained stationary (Newton, 2001).

A measuring device consisting of a tripod with a rigid tape measure, parallel to the ground, was placed at the level of each patient's acromion. The patients placed both arms at $90^{\circ}$ flexion, with the elbows and hands fully extended. They then reached as far as possible while holding the posture for 2 to $3 \mathrm{~s}$ without lifting their feet off the ground (Newton, 2001).

Dynamic balance. Dynamic balance was assessed using the Y Balance Test KitTM, which has been shown to have excellent inter-rater and intrarater reliability (intraclass correlation coefficient [ICC], 0.91 intrarater; 0.99 inter-rater) (Plisky et al., 2009).

The device consists of a support platform on which 3 tube-shaped pieces are attached in the anterior, posteromedial, and posterolateral directions of reach. The posterior tubes was placed at $135^{\circ}$ to the anterior tube, with $45^{\circ}$ between the posterior tubes. Each tube is marked at $5 \mathrm{~mm}$ increments for measurement purposes. The participant pushes a target (range indicator) along the tube, which indicates how far the foot is from the indicator. The target remains on the tape measure after the test is performed, indicating the most accurate range distance (Plisky et al., 2009). Participants stand on the central footrest supporting themselves on one leg and were asked to reach the maximum distance possible in the anterior, posteromedial, and posterolateral directions with the free leg. The maximum distance is measured by reading the tape measure at the edge of the range indicator, at the point where the most distal part of the foot reached. The test was repeated if the participant 1) could not maintain a unipedal posture on the platform (i.e., if they touched the ground with the foot or fell off the platform), 2) could not maintain foot contact with the indicator range in the target area while in motion (e.g., kicking the range indicator), 3) used the range indicator for posture support (e.g., placing the foot on the range indicator), or 4) did not return the range foot to the home position under control (Powden et al., 2019).

\section{- Secondary variables}

Pain intensity. Self-reported pain intensity was assessed using the Spanish version of the VAS, which consisted of a $10-\mathrm{cm}$ line with two ends representing the extreme states of "no pain" and "pain as severe as possible". The VAS has demonstrated good retest reliability $(r=0.94$; ICC, 0.97) (Bijur et al., 2001).

Self-efficacy in chronic pain. Self-efficacy in chronic pain was assessed using the Spanish version of the Chronic Pain Self-Efficacy Scale, which has good internal consistency (Cronbach's $\alpha$ 0.91) (Martín-Aragón et al., 1999). The scale was developed to measure perceived self-efficacy and the ability to deal with the consequences of pain among patients with chronic pain. The Spanish version of this scale, consisting of 19 items, is a selfadministered instrument with 3 domains that assess self-efficacy for pain management, physical functioning, and symptom management (MartínAragón et al., 1999). The total scores on this scale are obtained by summing the participants' responses to 
each item, with higher scores indicating greater selfefficacy to control pain (Martín-Aragón et al., 1999).

Catastrophism in the presence of pain. The Spanish version of the Pain Catastrophizing Scale is a reliable and valid measure of pain catastrophizing (Cronbach's $\alpha, 0.79$; ICC, 0.84) (García Campayo et al., 2008). The scale consists of 13 items and 3 factors: rumination (constant worry and inability to inhibit pain-related thoughts, 4 items), desperation (loss of hope for achieving something or for the disappearance of some physical and/or psychological aspect detrimental to health, 6 items) and magnification (exaggeration of the unpleasantness of pain, 3 items). Items are answered using a numerical value between 0 (none) and 4 (all the time), resulting in a maximum score of 52 points, with higher scores indicating greater pain catastrophizing (García Campayo et al., 2008).

Kinesiophobia (fear of movement). Fear of movement or kinesiophobia was assessed using the 11-item Spanish version of the Tampa Kinesiophobia Scale, whose reliability and validity have been demonstrated (Cronbach's $\alpha, 0.81$ ) (Gómez-Pérez et al., 2011). The scale is composed of 2 subscales, one related to fear of physical activity and the other related to fear of injury. The final score can range from 11 to 44 points, with higher scores indicating a higher perception of kinesiophobia (Gómez-Pérez et al., 2011).

\section{Statistical analysis}

An analysis of the sociodemographic and clinical data was performed and summarized using frequencies, descriptive statistics and tables. The data analysis was performed using SPSS Version 27.0 (IBM Corporation, Armonk, NY). Categorical variables are shown as frequencies and percentages.

The quantitative results of the study are represented by descriptive statistics (confidence interval, mean and standard deviation [SD]). For all variables, the $\mathrm{z}$-score was assumed to be normal according to the central limit theorem because all groups had at least 30 patients. Student's t-test was used for group comparisons for all variables.
We calculated the effect size using Cohen's method for multiple comparisons of the study variables. According to Cohen's method, the magnitude of the effect was classified as small $(0.20$ 0.49 ), medium (0.50-0.79), or large (0.80) (Cohen, 1973).

The associations between the psychological variables and the physical variables were examined using Pearson's correlation coefficients. A Pearson correlation coefficient $>0.60$ indicates a strong correlation, a coefficient between 0.30 and 0.60 indicates a moderate correlation, and a coefficient $<0.30$ indicates a low or very low correlation (Mouri, 2013).

\section{RESULTS}

The sample consisted of 60 patients with nonspecific CLBP (26 women and 34 men). Table 1 shows the participants' sociodemographic characteristics, with no significant differences in any variable between the two groups.

\section{Main variables}

Student's t-test revealed that there were significant differences between the groups in dynamic balance with the right leg $(\mathrm{t}=2.43 ; \mathrm{P}=$ $0.01 ; \mathrm{d}=0.59)$ and the left leg $(\mathrm{t}=3.60 ; \mathrm{P}=<0.001 ; \mathrm{d}$ $=0.93)$. In contrast, there were no significant differences between the groups for the reach functional test in forward direction $(\mathrm{t}=1.07 ; \mathrm{P}=0.8$; $\mathrm{d}=0.26)$, left direction $(\mathrm{t}=0.98 ; \mathrm{P}=0.32 ; \mathrm{d}=0.25)$ and right direction $(\mathrm{t}=1.26 ; \mathrm{P}=0.21 ; \mathrm{d}=0.33)$. Table 2 shows the comparisons between groups for the physical variables.

\section{Secondary variables}

The high disability group showed higher levels of kinesiophobia $(\mathrm{t}=-2.41 ; \mathrm{P}=0.01 ; \mathrm{d}=-0.63)$ and lower levels of self-efficacy $(\mathrm{t}=2.56 ; \mathrm{P}=0.01 ; \mathrm{d}=$ 0.66 ), differences that were statistically significant on the basis of Student's t-test. There were no significant differences in the level of catastrophism $(\mathrm{t}=-1.85 ; \mathrm{P}$ $=0.06 ; \mathrm{d}=-0.47)$, in the desperation subscale $(\mathrm{t}=$ $1.48 ; \mathrm{P}=0.14 ; \mathrm{d}=-0.37$ ) or in the rumination subscale $(\mathrm{t}=-1.33 ; \mathrm{P}=0.18 ; \mathrm{d}=-0.35)$. However, there were 
significant differences in the magnification subscale $(\mathrm{t}=-2.33 ; \mathrm{P}=0.02 ; \mathrm{d}=-0.62)$, with higher scores for those with a high level of disability. Table 3 shows the group comparisons for the psychological variables.

Table 1. Descriptive analysis of clinical and sociodemographic data.

\begin{tabular}{|c|c|c|c|}
\hline Measures & $\begin{array}{l}\text { Low level of } \\
\text { diability } \\
(\mathrm{n}=30)\end{array}$ & $\begin{array}{l}\text { High level of } \\
\text { disability } \\
(\mathrm{n}=30)\end{array}$ & $\begin{array}{l}\text { P value, T-test } \\
\text { (independent } \\
\text { samples) or chi- } \\
\text { square test }\end{array}$ \\
\hline $\mathrm{Age}^{\mathrm{a}}$ & $40.80 \pm 15.35$ & $40.77 \pm 14.14$ & .99 \\
\hline Gender $^{\mathbf{b}}$ & & & 1.00 \\
\hline male & $17(56.7)$ & $17(56.7)$ & \\
\hline female & $13(43.3)$ & $13(43.3)$ & \\
\hline $\mathrm{BMI}^{\mathrm{a}}$ & $24.6 \pm 4.2$ & $25.5 \pm 4.9$ & .47 \\
\hline Marital Status ${ }^{b}$ & & & .71 \\
\hline Single & $10(33.3)$ & $11(36.7)$ & \\
\hline Stable partner & $7(23.3)$ & $5(16.7)$ & \\
\hline Married & $8(26.7)$ & $10(33.3)$ & \\
\hline Divorced & $5(16.7)$ & $3(10)$ & \\
\hline Widowed & $0(0)$ & $1(3.3)$ & \\
\hline Education Level ${ }^{b}$ & & & .67 \\
\hline $\begin{array}{l}\text { Primary } \\
\text { education }\end{array}$ & $3(10)$ & $5(16.7)$ & \\
\hline $\begin{array}{l}\text { Secondary } \\
\text { education }\end{array}$ & $8(26.7)$ & $6(20)$ & \\
\hline $\begin{array}{l}\text { University } \\
\text { studies }\end{array}$ & $19(63.3)$ & $19(63.3)$ & \\
\hline Medcation Intake ${ }^{b}$ & & & .22 \\
\hline Yes & $5(15.7)$ & $9(30)$ & \\
\hline No & $25(83.3)$ & $21(70)$ & \\
\hline Pain intensity ${ }^{a}$ & $43.8 \pm 14.5$ & $47.2 \pm 15.1$ & .37 \\
\hline Chronicity ${ }^{a}$ & $23.9 \pm 25.8$ & $42.3 \pm 69.5$ & .18 \\
\hline Frequency of pain ${ }^{a}$ & $15.3 \pm 9.3$ & $19.2 \pm 9.7$ & .11 \\
\hline $\begin{array}{l}\text { Frequency of } \\
\text { medication }^{\text {a }}\end{array}$ & $2.1 \pm 6$ & $6.2 \pm 11.4$ & .08 \\
\hline
\end{tabular}

Values presented in mean \pm standard deviation, median and interquartile range or number $(\%)$; $* \mathrm{P}<.05 ; * * \mathrm{P}<.01$; ${ }^{\text {a }} \mathrm{T}$-Student, ${ }^{\mathrm{b}}$ frequency statistics. Bmi: Body mass index

\section{Correlation analysis}

Table 4 shows the results of the correlation analysis, which examined the bivariate relationships between the psychological variables and the physical variables. For the high disability group, the analysis revealed no correlation between the study variables. For the low disability group, in contrast, the strongest correlations were between the catastrophism level and the previous functional scope $(\mathrm{r}=-.457 ; \mathrm{P}<0.01)$ and between the degree of self-efficacy in the presence of chronic pain and the reach distance with the right leg $(\mathrm{r}=.483 ; \mathrm{P}<0.01)$ and the left leg $(\mathrm{r}=$ $.461 ; \mathrm{P}<0.05)$ (Table 4).

\section{DISCUSSION}

The main objective of this study was to evaluate postural stability and dynamic balance in patients with nonspecific CLBP based on their level of disability. The results of this study showed no statistically significant differences between the groups in postural stability, but there were significant differences in dynamic balance, with the group with a higher disability index showing poorer dynamic balance. Previous studies have shown that patients with CLBP have balance disorders, and it has been observed that a history of LBP episodes can be considered a risk factor for balance problems. Hooper et al. evaluated dynamic balance in patients with CLBP, patients with acute LBP, and asymptomatic participants and concluded that presenting symptoms in the lumbopelvic region significantly alters the dynamic balance compared with the asymptomatic group, regardless of symptom chronicity (Hooper et al., 2016). These dynamic balance disorders might also be due to fear of movement in certain directions due to the possibility of pain, given that patients with CLBP have a greater activation of the amygdala than asymptomatic participants when making certain movements (Meier et al., 2016; Hartvigsen et al., 2018). 
Table 2. Descriptive and comparative analysis between groups for physical variables.

\begin{tabular}{lccc}
\multicolumn{1}{c}{ Measures } & $\begin{array}{c}\text { Low level of diability } \\
(\mathbf{n}=30)\end{array}$ & $\begin{array}{c}\text { High level of disability } \\
(\mathbf{n}=30)\end{array}$ & $\begin{array}{c}\text { Difference of means }(\mathbf{9 5 \%} \mathrm{Cl}) ; \text { Effect size } \\
(\mathbf{d})\end{array}$ \\
Forward functional reach & $25.3 \pm 5.3$ & $23.8 \pm 6$ & $1.58(-1.4$ a 4.51$) ; \mathrm{d}=.26$ \\
Right lateral Functional range & $22.4 \pm 5.5$ & $20.4 \pm 6.5$ & $2(-1.1$ a 5.1$) ; \mathrm{d}=.33$ \\
Left lateral Functional range & $22.2 \pm 5.8$ & $20.8 \pm 5.2$ & $1.4(-1.5$ a 4.3$) ; \mathrm{d}=.25$ \\
Reach distance right leg (YBT) & $91.9 \pm 18.1$ & $80.8 \pm 19.7$ & $11.9(2.1 \text { a } 21.6)^{*} ; \mathrm{d}=.59$ \\
& & & $15.35(6.8 \text { a } 23.9)^{* *} ; \mathrm{d}=.93$
\end{tabular}

Values presented in mean \pm standard deviation; $* \mathrm{P}<.05$; ** $\mathrm{P}<.01$. YBT: Y Balance Test.

Tsigkanos et al. determined that patients with this clinical problem have a greater number of hip strategies than ankle strategies to maintain balance, and this difference could lead to poorer dynamic balance (Tsigkanos et al., 2016). However, there is a lack of evidence regarding the determinants of authors of these studies concluded that patients with chronic musculoskeletal pain present less static stability compared with asymptomatic participants, in addition to associating this variable with decreased movement, increased disability, and other psychological variables such as decreased self-

Table 3. Descriptive and comparative analysis between groups for psychological variables.

\begin{tabular}{|c|c|c|c|}
\hline Measures & $\begin{array}{l}\text { Low level of diability } \\
\qquad(n=30)\end{array}$ & $\begin{array}{l}\text { High level of disability } \\
\qquad(n=30)\end{array}$ & $\begin{array}{c}\text { Difference of means }(95 \% \mathrm{CI}) \text {; Effect } \\
\text { size (d) }\end{array}$ \\
\hline Disability & $6.3 \pm 1.4$ & $10.5 \pm 2.8$ & $-6.3(-8.5 \text { a }-4)^{* *} ; d=-1.89$ \\
\hline Catastrophism & $13.4 \pm 8.8$ & $18 \pm 10.5$ & $-4.6(-9.6$ a 0.4$) ; d=-.47$ \\
\hline Rumination & $4.9 \pm 3.5$ & $6.2 \pm 4$ & $-1.3(-3.2$ a 0.65$) ; d=-.35$ \\
\hline Magnification & $3 \pm 2.1$ & $4.6 \pm 3$ & $-1.6(-2.9 \text { a }-0.2)^{*} ; d=-.62$ \\
\hline Hopelessness & $5.5 \pm 4.1$ & $7.2 \pm 5$ & $-1.8(-4.1$ a 0.6$) ; d=-.37$ \\
\hline Kinesiophobia & $24 \pm 6$ & $27.7 \pm 5.8$ & $-3.7(-6.8$ a -.63$) * ; d=-.63$ \\
\hline Chronic pain self-efficacy & $150.7 \pm 25.3$ & $132 \pm 30.9$ & $18.66(4.1 \text { a } 33.3)^{*} ; d=.66$ \\
\hline
\end{tabular}

Values presented in mean \pm standard deviation; $* \mathrm{P}<.05 ; * * \mathrm{P}<.01$.

dynamic balance, such as the disability index. Thus, numerous authors have hypothesized that greater intensity and duration of pain and greater physical disability might correlate with a decrease in functional performance in terms of static and dynamic posture, in addition to producing alterations in the proprioceptive mechanism (Brech et al., 2012; Laird et al., 2014; Tsigkanos et al., 2016; Sadler et al., 2017; Tong et al., 2017).

Regarding postural and static stability, our study found no intergroup differences; however, we found several studies whose results contrast to ours. The efficacy and catastrophism (Sánchez-Herán et al., 2016; Gomes et al., 2018; La Touche et al., 2019). In their study, Brech et al. suggested that individuals with CLBP have impaired postural stability compared with those who do not have a history of pain, especially in conditions with higher postural demands (Brech et al., 2012). Another study by da Silva et al. found significant differences between participants with CLBP and asymptomatic participants when performing 5 static balance tests, while incorporating variables such as the use or not of the visual system or the positioning of the feet in 
parallel or in tandem (da Silva et al., 2018). However, there is disagreement on these variables, given that other authors found no remarkable abnormalities in postural stability between individuals with CLBP and disability and higher scores in terms of catastrophism and kinesiophobia (La Touche et al., 2019). Based on the evidence and our results, we suggest that selfefficacy is a determinant in terms of the disability

Table 4. Correlation analysis examining the bivariate relationships between the psychological variables and the physical variables.

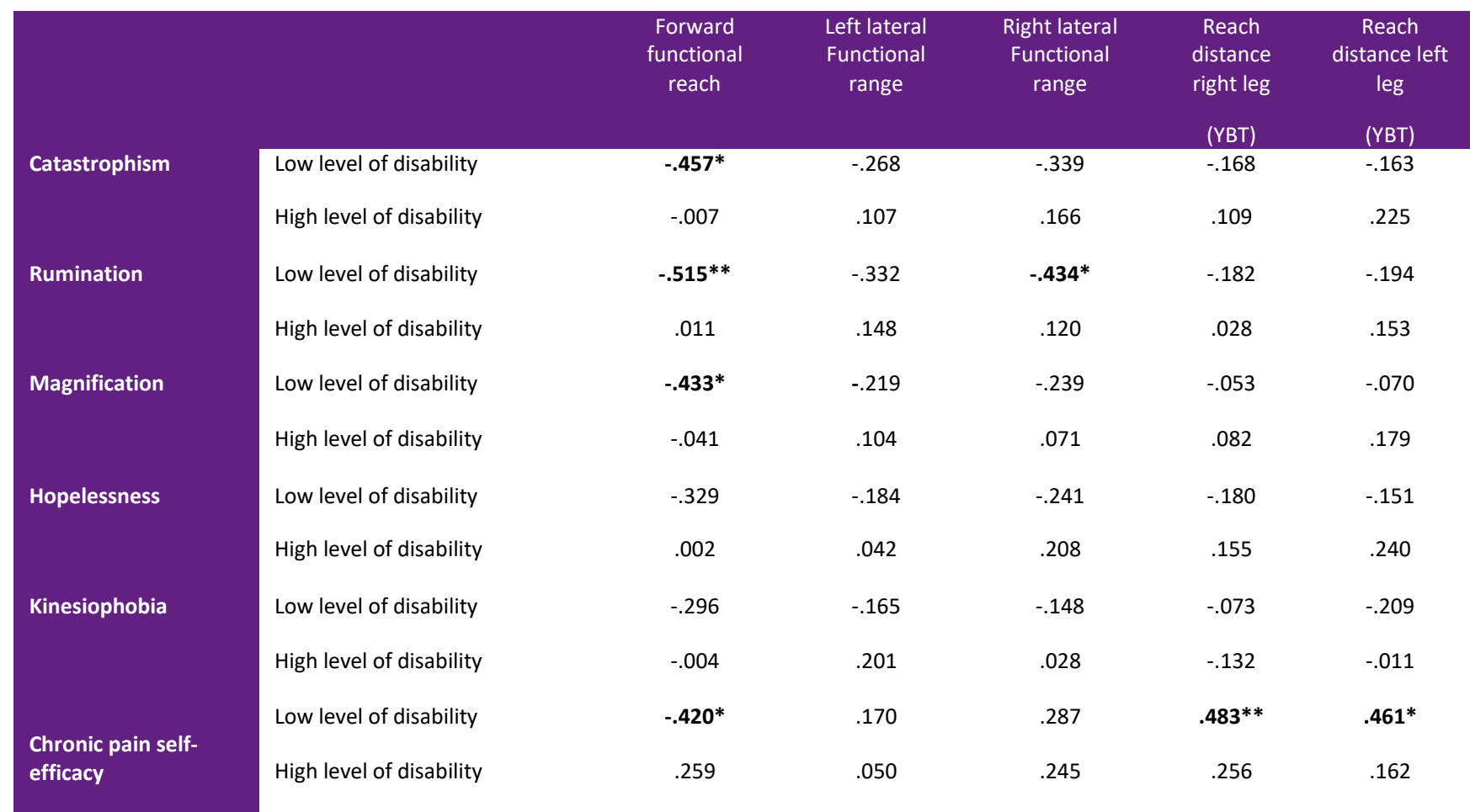

$* \mathrm{P}<.05 ; * * \mathrm{P}<.01$

asymptomatic participants under normal conditions in the anteroposterior and mid-lateral direction. However, there were significant differences when including unstable surfaces or when overriding the visual system (Mientjes and Frank, 1999; della Volpe et al., 2006).

Regarding the secondary objective, our study revealed that patients with CLBP with a higher level of disability presented a significantly lower level of self-efficacy and a higher level of kinesiophobia. With respect to the influence of psychosocial factors on individuals with CLBP, there is significant evidence in the literature that negative psychosocial factors are associated with a greater perception of pain and disability (Meyer et al., 2009). A study on patients with CLBP showed that the degree of selfefficacy presented a moderate negative correlation with the disability index, in addition to the fact that patients with low self-efficacy showed greater perceived by these patients (Woby et al., 2007; de Moraes Vieira et al., 2014). In terms of kinesiophobia, studies have shown that fear of movement is one of the most influential psychological factors in terms of disability in patients with chronic pain (Sullivan et al., 2009; GrandeAlonso et al., 2020; Nieto-García et al., 2019). In support of our results, Sullivan et al. reported that patients with CLBP who have greater kinesiophobia have a greater perception of pain than patients with CLBP who do not have kinesiophobia (Sullivan et al., 2009). In addition, fear of movement is strongly related to perceived disability in these patients, which, together with catastrophic thoughts, are considered predictors of chronic pain (Grotle et al., 2010).

This study has certain limitations. First, the results should be interpreted with caution because this was an observational study, and therefore causal 
relationships cannot be established. Another important limitation is the lack of assessment of the participants' physical activity levels, which could have influenced the perceived difficulty and their ability to perform the motor tasks (La Touche et al., 2019). Lastly, there was a significant limitation in the implementation of this study due to the state of alarm in Spain with the Covid-19 pandemic, which prevented us from enrolling the entire planned sample.

\section{CONCLUSION}

In conclusion, our study demonstrates that patients with CLBP with high levels of disability present significantly poorer dynamic balance compared with those with low levels of disability. In contrast, no significant differences were found between the groups in terms of static stability.

This study shows that patients with CLBP and high levels of disability have significantly higher levels of kinesiophobia and lower levels of selfefficacy in managing their pain compared with patients with CLBP with low levels of disability.

\section{Acknowledgements}

The authors would like to thank the Centro Superior de Estudios Universitarios CSEU La Salle for its services in editing this manuscript.

\section{HIGHLIGHTS}

$>$ Patients with CLBP with high levels of disability present significantly poorer dynamic balance compared with those with low levels of disability

$>$ Patients with CLBP and high levels of disability have significantly higher levels of kinesiophobia and lower levels of selfefficacy.

\section{REFERENCES}

Anema JR, Schellart AJM, Cassidy JD, Loisel P, Veerman TJ, Van Der Beek AJ. Can cross country differences in return- to-work after chronic occupational back pain be explained? An exploratory analysis on disability policies in a six country cohort study. J Occup Rehabil. 2009;19(4):419-26 DOI: http://dx.doi.org/10.1007/s10926-009-9202-3.

Berenshteyn Y, Gibson K, Hackett GC, Trem AB, Wilhelm M. Is standing balance altered in individuals with chronic low back pain? A systematic review. Vol. 41, Disability and Rehabilitation. Disabil Rehabil; 2019. p. 1514-23 DOI: http://dx.doi.org/10.1080/09638288.2018.1433240.

Bijur PE, Silver W, Gallagher EJ. Reliability of the visual analog scale for measurement of acute pain. Acad Emerg Med. 2001;8(12):1153-7.

Brech GC, Andrusaitis SF, Vitale GF, Greve JMD. Correlation of disability and pain with postural balance among women with chronic low back pain. Clinics (Sao Paulo). Hospital das Clinicas da Faculdade de Medicina da Universidade de Sao Paulo; 2012;67(8):959-62 DOI: http://dx.doi.org/10.6061/CLINICS/2012(08)17.

Brumagne S, Janssens ÆL, Knapen S, Claeys ÆK. Persons with recurrent low back pain exhibit a rigid postural control strategy. 2008;1177-84 DOI: http://dx.doi.org/10.1007/s00586-008-0709-7.

Cohen J. Eta-squared and partial eta-squared in fixed factor anova designs. Educ Psychol Meas. 1973;33(1):107-12 DOI: http://dx.doi.org/10.1177/001316447303300111.

von Elm E, Altman DG, Egger M, Pocock SJ, Gøtzsche PC, Vandenbroucke JP. The Strengthening the Reporting of Observational Studies in Epidemiology (STROBE) statement: guidelines for reporting observational studies. J Clin Epidemiol. 2008;61(4):344-9 DOI: http://dx.doi.org/10.1016/j.jclinepi.2007.11.008.

García Campayo J, Rodero B, Alda M, Sobradiel N, Montero J, Moreno S. [Validation of the Spanish version of the Pain Catastrophizing Scale in fibromyalgia]. Med Clin (Barc). 2008;131(13):487-92.

Gomes PKA, Silva RBC, de Freitas IMD, Gomes CAF de P, Souza C da S, de Sousa NTA, Dibai-Filho AV. Evaluation of Postural Balance and Articular Mobility of the Lower Limbs in Chronic Neck Pain Patients by Means of LowCost Clinical Tests. J Manipulative Physiol Ther. Mosby Inc.; 2018;41(8):658-64 DOI: http://dx.doi.org/10.1016/j.jmpt.2018.03.006.

Gómez-Pérez L, López-Martínez AE, Ruiz-Párraga GT. Psychometric Properties of the Spanish Version of the Tampa Scale for Kinesiophobia (TSK). J Pain. 2011;12(4):425-35 DOI: http://dx.doi.org/10.1016/j.jpain.2010.08.004.

Grande-Alonso M, Muñoz-García D, Cuenca-Martínez F, Delgado-Sanz L, Prieto-Aldana M, La Touche R, GilMartínez A. Relationship between healthcare seeking and pain expansion in patients with nonspecific chronic low back pain. PeerJ. PeerJ; 2020;8:e8756 DOI: http://dx.doi.org/10.7717/peerj.8756.

Grotle M, Foster NE, Dunn KM, Croft P. Are prognostic indicators for poor outcome different for acute and chronic low back pain consulters in primary care? Pain. 
2010;151(3):790-7

DOI:

http://dx.doi.org/10.1016/j.pain.2010.09.014.

Hartvigsen J, Hancock MJ, Kongsted A, Louw Q, Ferreira ML, Genevay S, Hoy D, Karppinen J. Series Low back pain 1 What low back pain is and why we need to pay attention. 2018;6736(18) DOI: http://dx.doi.org/10.1016/S01406736(18)30480-X.

Hashmi JA, Baliki MN, Huang L, Baria AT, Torbey S, Hermann KM, Schnitzer TJ, Apkarian AV. Shape shifting pain: chronification of back pain shifts brain representation from nociceptive to emotional circuits. Brain. 2013;136(Pt 9):2751-68 DOI: http://dx.doi.org/10.1093/brain/awt211.

Herndon CM, Zoberi KS, Gardner BJ. Common questions about chronic low back pain. Am Fam Physician. 2015;91(10):708-14.

Hooper TL, James CR, Brismée JM, Rogers TJ, Gilbert KK, Browne KL, Sizer PS. Dynamic balance as measured by the Y-Balance Test is reduced in individuals with low back pain: A cross-sectional comparative study. Phys Ther Sport. Elsevier Ltd; 2016;22:29-34 DOI: http://dx.doi.org/10.1016/j.ptsp.2016.04.006.

Hoy D, Bain C, Williams G, March L, Brooks P, Blyth F, Woolf A, Vos T, Buchbinder R. A systematic review of the global prevalence of low back pain. Arthritis Rheum. 2012;64(6):2028-37

DOI: http://dx.doi.org/10.1002/art.34347.

Hoy D, Brooks P, Blyth F, Buchbinder R. The Epidemiology of low back pain. Best Pract Res Clin Rheumatol. 2010;24(6):769-81

DOI: http://dx.doi.org/10.1016/j.berh.2010.10.002.

Incidence I, Collaborators P. Global , regional , and national incidence, prevalence, and years lived with disability for 310 diseases and injuries , 1990 - 2015: a systematic analysis for the Global Burden of Disease Study 2015. 2017;1990-2015 DOI: http://dx.doi.org/10.1016/S01406736(16)31678-6.

Kovacs FM, Llobera J, Gil Del Real MT, Abraira V, Gestoso M, Fernández C, Primaria Group K-A. Validation of the spanish version of the Roland-Morris questionnaire. Spine (Phila Pa 1976). 2002;27(5):538-42.

Krismer M, van Tulder M, Low Back Pain Group of the Bone and Joint Health Strategies for Europe Project. Strategies for prevention and management of musculoskeletal conditions. Low back pain (non-specific). Best Pract Res Clin Rheumatol. 2007;21(1):77-91 DOI: http://dx.doi.org/10.1016/j.berh.2006.08.004.

Laird RA, Gilbert J, Kent P, Keating JL. Comparing lumbopelvic kinematics in people with and without back pain: A systematic review and meta-analysis. BMC Musculoskelet Disord. BioMed Central Ltd.; 2014;15(1) DOI: http://dx.doi.org/10.1186/1471-2474-15-229.

Lee S-K, Ahn S-H. Effects of balance evaluation comparison of dynamic balance and Y balance. J Exerc Rehabil. Korean Society of Exercise Rehabilitation; 2018;14(6):939-43 DOI: http://dx.doi.org/10.12965/jer.1836494.247.

Martín-Aragón GM, Pastor Mira M de los A, Rodríguez Martín J,
March M, Lledó A, López-Roig S, Et A. Percepción de autoeficacia en dolor crónico: adaptación y validación de la Chronic Pain Self-Efficacy Scale. Rev Psicol Salud. 1999;11(1-2):53-75.

Meier ML, Stämpfli P, Vrana A, Humphreys BK, Seifritz E, Hotz-Boendermaker S. Neural Correlates of Fear of Movement in Patients with Chronic Low Back Pain vs. Pain-Free Individuals. Front Hum Neurosci. Frontiers Media SA; 2016;10:386 DOI: http://dx.doi.org/10.3389/fnhum.2016.00386.

Meyer K, Tschopp A, Sprott H, Mannion AF. Association between catastrophizing and self-rated pain and disability in patients with chronic low back pain. J Rehabil Med. Sweden; 2009;41(8):620-5 DOI: http://dx.doi.org/10.2340/16501977-0395.

Mientjes MI, Frank JS. Balance in chronic low back pain patients compared to healthy people under various conditions in upright standing. Clin Biomech (Bristol, Avon). 1999;14(10):710-6.

de Moraes Vieira EB, de Goes Salvetti M, Damiani LP, de Mattos Pimenta CA. Self-efficacy and fear avoidance beliefs in chronic low back pain patients: coexistence and associated factors. Pain Manag Nurs. United States; 2014;15(3):593-602 DOI: http://dx.doi.org/10.1016/j.pmn.2013.04.004.

Mouri H. Log-normal distribution from a process that is not multiplicative but is additive. Physical review. E, Statistical, Nonlinear, and Soft Matter Physics. 2013;88(4) DOI: http://dx.doi.org/10.1103/physreve.88.042124.

Murray CJL, Lopez AD. Measuring the global burden of disease. Vol. 369, New England Journal of Medicine. Massachussetts Medical Society; 2013. p. 448-57 DOI: http://dx.doi.org/10.1056/NEJMra1201534.

Newton $\mathrm{R}$ a. Validity of the multi-directional reach test: a practical measure for limits of stability in older adults. $\mathrm{J}$ Gerontol A Biol Sci Med Sci. 2001;56(4):M248-52 DOI: http://dx.doi.org/10.1093/gerona/56.4.M248.

Nieto-García J, Suso-Martí L, La Touche R, Grande-Alonso M. Somatosensory and motor differences between physically active patients with chronic low back pain and asymptomatic individuals. Med. MDPI AG; 2019;55(9) DOI: http://dx.doi.org/10.3390/medicina55090524.

Plisky PJ, Gorman PP, Butler RJ, Kiesel KB, Underwood FB. The reliability of an instrumented device for measuring component of the Star Excursion Balance Test. N Am J Sports Phys Ther. 2009;4(2):92-9.

Powden CJ, Dodds TK, Gabriel EH. the Reliability of the Star Excursion Balance Test and Lower Quarter Y-Balance Test in Healthy Adults: a Systematic Review. Int J Sports Phys Ther. 2019;14(5):683-94 DOI: http://dx.doi.org/10.26603/ijspt20190683.

Rossignol M, Rozenberg S, Leclerc A. Epidemiology of low back pain: what's new? Joint Bone Spine. 2009;76(6):60813 DOI: http://dx.doi.org/10.1016/j.jbspin.2009.07.003.

Sadler SG, Spink MJ, Ho A, De Jonge XJ, Chuter VH. Restriction in lateral bending range of motion, lumbar 
lordosis, and hamstring flexibility predicts the development of low back pain: A systematic review of prospective cohort studies. BMC Musculoskelet Disord. BMC Musculoskeletal Disorders; 2017;18(1):1-15 DOI: http://dx.doi.org/10.1186/s12891-017-1534-0.

Sánchez-Herán Á, Agudo-Carmona D, Ferrer-Peña R, López-deUralde-Villanueva I, Gil-Martínez A, Paris-Alemany A, La Touche R. Postural Stability in Osteoarthritis of the Knee and Hip: Analysis of Association With Pain Catastrophizing and Fear-Avoidance Beliefs. PM R. $\begin{array}{lll}\text { Elsevier Inc.; 2016;8(7):618-28 DOI: } & \end{array}$ http://dx.doi.org/10.1016/j.pmrj.2015.11.002.

da Silva RA, Vieira ER, Fernandes KBP, Andraus RA, Oliveira MR, Sturion LA, Calderon MG. People with chronic low back pain have poorer balance than controls in challenging tasks. Disabil Rehabil. Disabil Rehabil; 2018;40(11):1294300 DOI: http://dx.doi.org/10.1080/09638288.2017.1294627.

Starkweather AR, Lyon DE, Kinser P, Heineman A, Sturgill JL, Deng X, Siangphoe U, Elswick RK, Greenspan J, Dorsey SG. Comparison of Low Back Pain Recovery and Persistence: A Descriptive Study of Characteristics at Pain Onset. Biol Res Nurs. 2016; DOI: http://dx.doi.org/10.1177/1099800416631819.

Sullivan MJL, Thibault P, Andrikonyte J, Butler H, Catchlove R, Larivière C. Psychological influences on repetition-induced summation of activity-related pain in patients with chronic low back pain. Pain. 2009;141(1-2):70-8 DOI: http://dx.doi.org/10.1016/j.pain.2008.10.017.

Tong MH, Mousavi SJ, Kiers H, Ferreira P, Refshauge K, van Dieën J. Is There a Relationship Between Lumbar Proprioception and Low Back Pain? A Systematic Review With Meta-Analysis. Arch Phys Med Rehabil. W.B. Saunders; 2017. p. 120-136.e2 DOI: http://dx.doi.org/10.1016/j.apmr.2016.05.016.

La Touche R, Grande-Alonso M, Arnes-Prieto P, Paris-Alemany A. How Does Self-Efficacy Influence Pain Perception, Postural Stability and Range of Motion in Individuals with Chronic Low Back Pain? Pain Physician. 2019;22(1):E113.

Tsigkanos C, Gaskell L, Smirniotou A, Tsigkanos G. Static and dynamic balance deficiencies in chronic low back pain. $\mathrm{J}$ Back Musculoskelet Rehabil. 2016;29(4):887-93 DOI: http://dx.doi.org/10.3233/BMR-160721.

della Volpe R, Popa T, Ginanneschi F, Spidalieri R, Mazzocchio $\mathrm{R}$, Rossi A. Changes in coordination of postural control during dynamic stance in chronic low back pain patients. Gait Posture. Netherlands; 2006;24(3):349-55 DOI: http://dx.doi.org/10.1016/j.gaitpost.2005.10.009.

Wadell G. The Back Pain Revolution. Churchill Livingstone 1998, editor. 2004.

Wajswelner H, Metcalf B, Bennell K. Clinical pilates versus general exercise for chronic low back pain: randomized trial. Med Sci Sports Exerc. 2012;44(7):1197-205 DOI: http://dx.doi.org/10.1249/MSS.0b013e318248f665.

Wideman TH, Sullivan MJL. Differential predictors of the long- term levels of pain intensity, work disability, healthcare use, and medication use in a sample of workers' compensation claimants. Pain. 2011;152(2):376-83 DOI: http://dx.doi.org/10.1016/j.pain.2010.10.044.

Woby SR, Urmston M, Watson PJ. Self-efficacy mediates the relation between pain-related fear and outcome in chronic low back pain patients. Eur J Pain. 2007;11(7):711-8 DOI: http://dx.doi.org/10.1016/j.ejpain.2006.10.009.

Woolf AD, Pfleger B. Burden of major musculoskeletal conditions. Bull World Health Organ. 2003;81(9):646-56.

Yavuzer G, Eser F, Karakus D, Karaoglan B, Stam HJ. The effects of balance training on gait late after stroke: a randomized controlled trial. Clin Rehabil. 2006;20(11):960-9 DOI: http://dx.doi.org/10.1177/0269215506070315.

Zusman M. Forebrain-mediated sensitization of central pain pathways: "non-specific" pain and a new image for MT. Man Ther. 2002;7(2):80-8. 